\title{
Synaptopodin Deficiency Ameliorates Symptoms in the 3xTg Mouse Model of Alzheimer's Disease
}

\author{
Etay Aloni, ${ }^{1}$ Efrat Oni-Biton, ${ }^{1}{ }^{\circledR}$ Micheal Tsoory, ${ }^{2}{ }^{\circledR D a l i a} \mathrm{H}$. Moallem, ${ }^{1}$ and ${ }^{\oplus}$ Menahem Segal $^{1}$ \\ Departments of ${ }^{1}$ Neurobiology, and ${ }^{2}$ Veterinary Resources, The Weizmann Institute, Rehovot 76100, Israel
}

Disruption in calcium homeostasis is linked to several pathologies and is suggested to play a pivotal role in the cascade of events leading to Alzheimer's disease (AD). Synaptopodin (SP) residing in dendritic spines has been associated with ryanodine receptor (RyR), such that spines lacking SP release less calcium from stores. In this work, we mated SPKO with 3xTg mice (3xTg/SPKO) to test the effect of SP deficiency in the AD mouse. We found that 6-month-old male 3xTg/SPKO mice restored normal spatial learning in the Barns maze, LTP in hippocampal slices, and expression levels of RyR in the hippocampus that were altered in the 3xTg mice. In addition, there was a marked reduction in 3xTg-associated phosphorylated tau, amyloid $\beta$ plaques, and activated microglia in $3 \times \mathrm{Tg} / \mathrm{SPKO}$ male and female mice. These experiments indicate that a reduction in the expression of SP ameliorates AD-associated phenotype in $3 \times \mathrm{Tg}$ mice.

Key words: 3xTg mouse; calcium; hippocampus; LTP; synaptopodin

\section{Significance Statement}

This study strengthens the proposed role of calcium stores in the development of AD-associated phenotype in the 3xTg mouse model, in that a genetic reduction of the functioning of ryanodine receptors using synaptopodin-knock-out mice ameliorates $\mathrm{AD}$ symptoms at the behavioral, electrophysiological, and morphological levels of analysis.

\section{Introduction}

Abnormality in intraneuronal calcium homeostasis has been suggested to play a pivotal role in the cascade of events leading to $\mathrm{AD}$ (Khachaturian, 1989; Mattson, 2010; Stutzmann and Mattson, 2011; Popugaeva and Bezprozvanny, 2013; Del Prete et al., 2014). Alterations in ryanodine receptor (RyR) expression were reported in patients with $\mathrm{AD}$ already at early stages of the disease (Kelliher et al., 1999; Bruno et al., 2012) and in animal models containing mutant presenilin 1 (PS1; Smith et al., 2005; Chakroborty et al., 2009). The 3xTg AD mouse model, which harbors PS1M146V, APPSwe, and tauP301L transgenes, develop amyloid plaques at 6 months of age and neurofibrillary tangles at 9 months of age (Oddo et al., 2003). In addition, synaptic plasticity impairments and cognitive impairments may be found even earlier (2-4 months of age), and were suggested as an early indication of the disease (Grigoryan et al., 2014; Clark et al., 2015).

\footnotetext{
Received Nov. 15, 2018; revised Jan. 18, 2019; accepted Feb. 18, 2019.

Author contributions: M.S. designed research; E.A., E.O.-B., M.T., and D.H.M. performed research; E.O.-B. contributed unpublished reagents/analytic tools; E.A., E.O.-B., M.T., and M.S. analyzed data; M.S. wrote the paper.

We thank Drs. E. Korkotian and R. Eilam for help with the morphological analysis, and Dr. S. Verbitsky for constructive comments on the manuscript. This research was supported by a grant from the German Israeli Foundation. M.T. is the incumbent of the Carolito Stiftung Research Fellow Chair in Neurodegenerative Diseases.

The authors declare no competing financial interests.

Correspondence should be addressed to Menahem Segal at menahem.segal@weizmann.ac.il.

https://doi.org/10.1523/JNEUROSCI.2920-18.2019

Copyright $\odot 2019$ the authors
}

However, the mechanisms through which these mutations cause synaptic plasticity impairments remain elusive. 3xTg mice exhibits high expression of RyR in the hippocampus, an increase in RyR-evoked calcium release, and plasticity in response to synaptic transmission (Stutzmann et al., 2006; Chakroborty et al., 2009).

Synaptopodin (SP) is an actin-binding protein residing in dendritic spines. It is essential for the formation of a spine apparatus (SA), which is a specialized form of ER found in dendritic spines. SP clusters in spines have been associated with RyR, which is more abundant in spines that express $\mathrm{SP}^{+}$than in ones that do not (Vlachos et al., 2009). SP regulates the release of calcium from stores in dendritic spines (Korkotian and Segal, 2011). SPKO mice are viable; however, they lack SA, and demonstrate longterm potentiation (LTP) deficiencies and impaired spatial learning (Deller et al., 2007; Jedlicka and Deller, 2017). In addition, neurons from SPKO mice lack homeostatic synaptic plasticity (Vlachos et al., 2013). Interestingly, SP expression in the hippocampus is downregulated in patients with dementia with Lewy bodies, Parkinson's disease dementia, mild cognitive impairments, and AD (Reddy et al., 2005; Counts et al., 2014; Datta et al., 2017).

The present study examined the interaction between SP and the $3 x T g$ mouse model of AD. The data indicate that SP deficiency ameliorates symptoms of $\mathrm{AD}$ in the $3 \mathrm{xTg}$ mice and restores normal synaptic plasticity. 

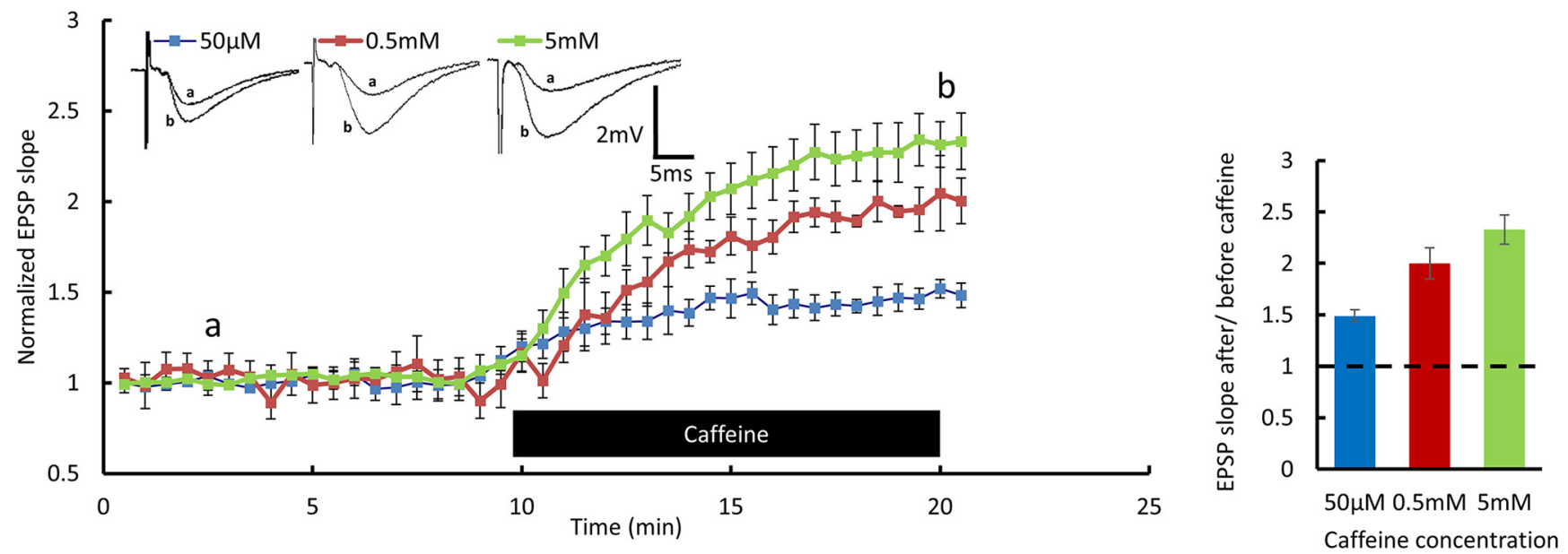

Figure 1. Caffeine enhances EPSPs in wt mice: extracellular field potential recordings of EPSP in a Schaffer collateral of the hippocampus. EPSP slope measured for 10 min of baseline and during caffeine perfusion shown in the bar below the record, in three different concentrations. Sample EPSPs recorded at the time points " $\mathrm{a}$ " and " $\mathrm{b}$ " (before and after caffeine perfusion, respectively) are presented above the record. Bar graph summarizes potentiation results at the $b$ time point. Data are presented as the mean \pm SEM in this and the following figures. Six-month-old male mice; $n=$ 4-5 slices taken from 3 mice/concentration.

A
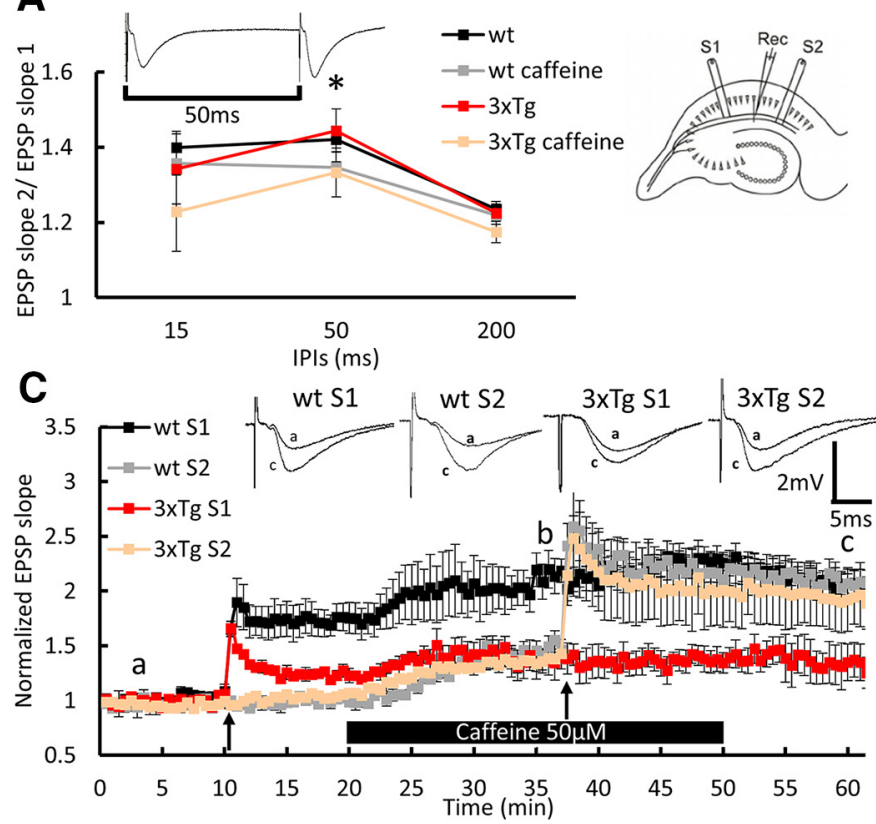

B
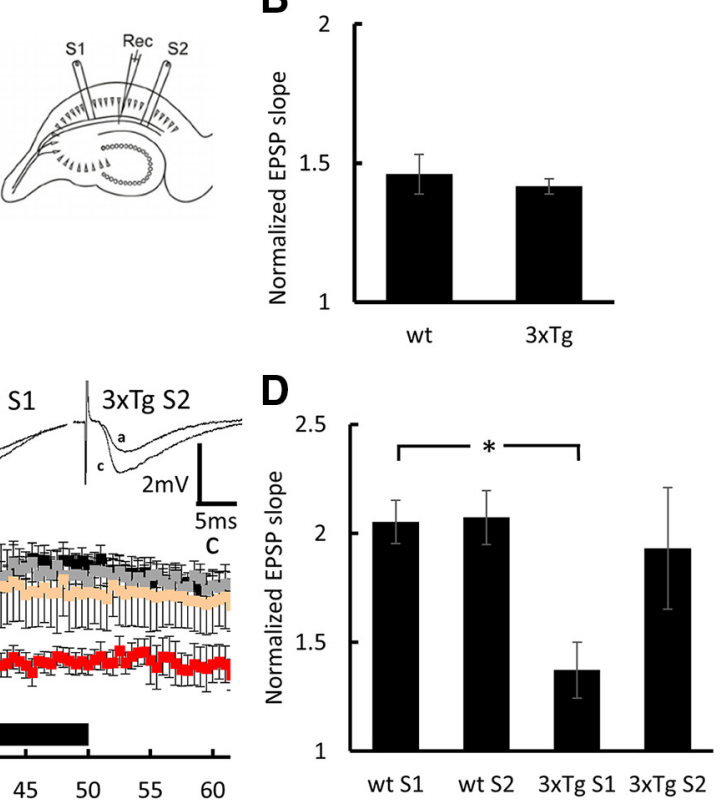

Figure 2. Caffeine facilitates LTP in the 3xTg mice: extracellular EPSPs recorded in stratum radiatum of the hippocampus. $A$, Paired-pulse ratio at three different interpulse intervals (IPIs) before and after $20 \mathrm{~min}$ of $50 \mu \mathrm{m}$ caffeine perfusion at times indicated by " $\mathrm{a}$ " and " $\mathrm{b}$," respectively, showing a significant effect of caffeine perfusion at $50 \mathrm{~ms}$ interval (wt: before, $1.42 \pm 0.032$; after, $1.35 \pm$ $0.016 ; \mathrm{t} 3=3.427 ; p=0.042 ; 3 \mathrm{xTg}$ : before, $1.44 \pm 0.058 ; \mathrm{after}, 1.33 \pm 0.065 ; \mathrm{t} 4=3.038 ; p=0.037$, paired $t$ test). Sample of two consecutive EPSPs recorded at a $50 \mathrm{~ms}$ interpulse interval are presented above the record. $\boldsymbol{B}$, Bar graph presenting the effect of caffeine on EPSP slope in wt and 3xTg S2 at time point b. C, Normalized EPSP slopes recorded in response to stimulation of two pathways, as presented in the diagram above the record. Slices were perfused with $50 \mu \mathrm{m}$ caffeine for 30 min during the bar shown below the record. First, HFS was delivered in the slope 1 (S1) pathway and the second HFS was delivered in the slope 2 (S2) pathway; both marked by black arrows. Sample EPSPs recorded at the time points a and " $c$ " are presented above the record. D, Bar graph summarizes LTP results at time point $c$, showing significant reduction in LTP in the 3xTg group compared with the wt group ( $p=0.0037$, two-sample $t$ test) that was restored back to normal in response to the $\mathrm{S} 2$ pathway stimulation during the perfusion of caffeine. Six-month-old male mice; $n=4-5$ slices taken from 3 mice/group. ${ }^{*} p<0.05$.

\section{Materials and Methods}

Animals. Experiments were approved by the local Institutional Animal Care and Use Committee. Mice were maintained on a $12 \mathrm{~h}$ light/dark cycle, and were allowed free access to food and water. By crossing $3 \mathrm{xTg}$ with SPKO mouse lines, we obtained a new mouse line that was both harboring the three transgenic mutations originally found in the $3 \times \mathrm{Tg}$ mouse line and was lacking the SP gene in both alleles of its DNA (3xTg/ SPKO). In our study, we used both male and female mice.
Genotyping. To examine the mouse genotype, we extracted DNA from the edge of the tail tissue using a standard DNeasy Tissue Kit (Qiagen). We then amplified the genes of interest using PCR [PS1 primers: forward (F), 5'-AATAGAGAACGGCAGGAGCA; reverse (R), 5'-GCCATGAGGGCACTAATCAT; APP primers: F, 5'-AGGACTGACCACTC GACCAG; R, 5'-GTAGGTGGAAATTCTAGCATCAT; Microtubule Associated Protein Tau primers: F, 5'-TGAACCAGGATG-GCTGAG; R, 5'-TTGTCATCGCTTCCAGTCC; SYNPO (SP) primers: 1, 5'-GCGG 
A
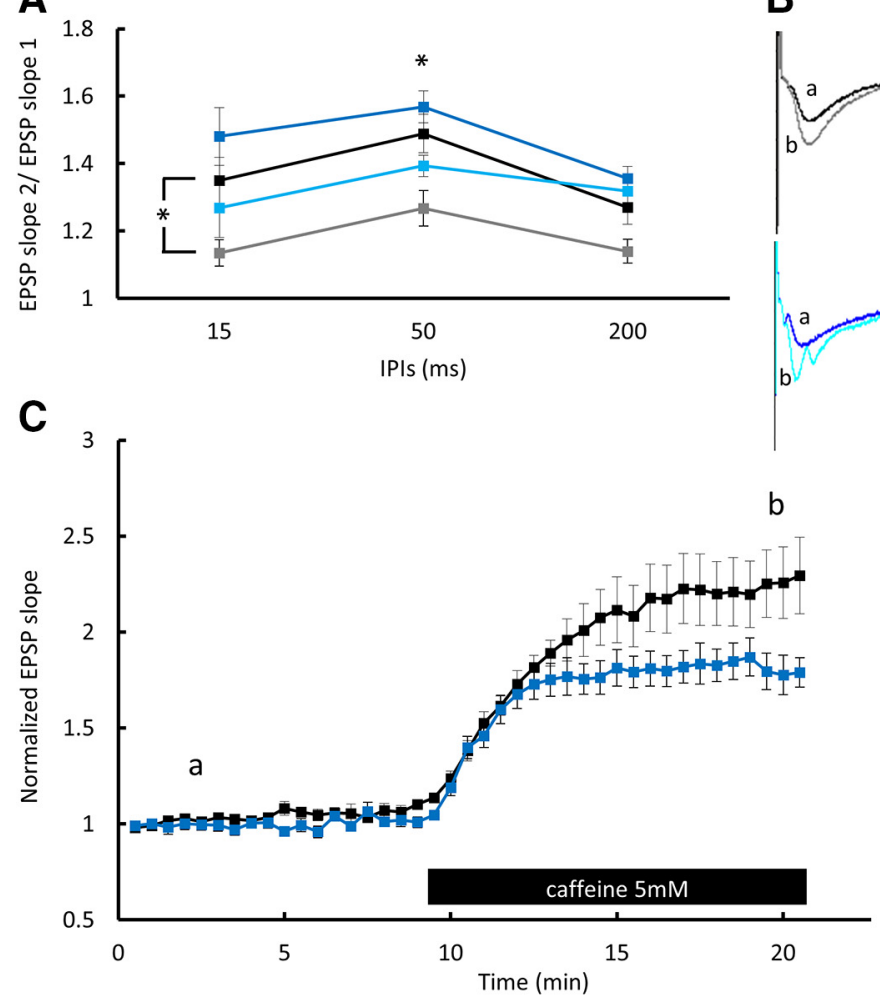

B

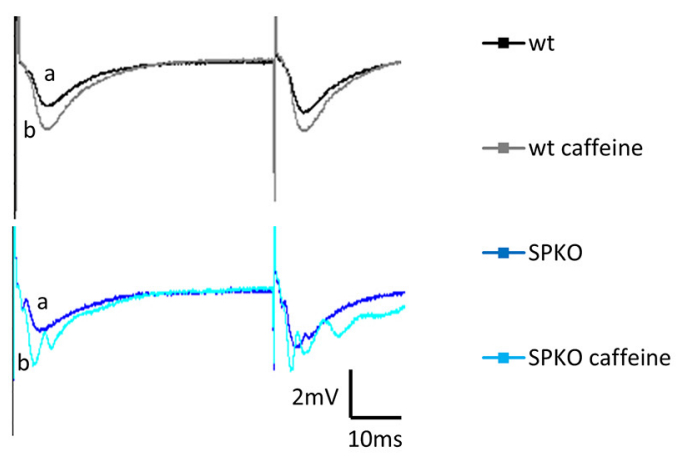

Figure 3. EPSP elevation by caffeine is reduced in SPKO mice: population EPSPs recorded in stratum radiatum of 6-month-old male mice of the hippocampus. $A$, Paired-pulse ratio at three different interpulse intervals (IPIs) before and after $10 \mathrm{~min}$ of $5 \mathrm{~mm}$ caffeine perfusion at times indicated in C by "a" and "b," respectively, showing a significant effect of caffeine perfusion in the wt group at $15 \mathrm{~ms}$ intervals (wt: before, $1.35 \pm 0.07$; after, $1.135 \pm 0.04 ; \mathrm{t} 21=2.33 ; p=0.03$, paired $t$ test $n=9$ slices in 3 mice) and at 50 ms intervals in both groups (wt: before, $1.49 \pm 0.06$; after, $1.27 \pm 0.05 ; t=2.68 ; p=0.014$, paired $t$ test $; n=9$ slices in 3 mice; SPKO: before, $1.57 \pm 0.05$; after, $1.39 \pm 0.03 ; t=3 ; p=0.005$, paired $t$ test; $n=13$ slices in 4 mice). $\boldsymbol{B}$, Sample of two consecutive EPSPs recorded at $50 \mathrm{~ms}$ interpulse interval before and after $5 \mathrm{~mm}$ caffeine perfusion. $C$, EPSPs slope measured during $10 \mathrm{~min}$ at baseline and following caffeine perfusion shown in the bar below the record. $D$, Bar graph presenting the effect of $5 \mathrm{~mm}$ caffeine on EPSP slope in wt and SPKO slices at time point b showing significant reduction in the effect of caffeine in the SPKO group (wt, $2.25 \pm 0.18 ;$ SPKO, $1.72 \pm 0.08 ; \mathrm{t} 20=2.35 ; p=0.029$, unpaired $t$ test $; n=9$ and 13 slices in 3 and 4 mice, respectively). ${ }^{*} p<0.05$.

TGGCTGACTGTGGTGACT; 2, 5'-CAGGCGCAGGCAGAGGGTGA ACG; and 3, 5'-CCAGCTGGCGAAAGGGGGATGTG] and ran the samples on agarose gels ( $1 \%$ agarose in Tris buffer) using ethidium bromide as a DNA fluorescent indicator.

Behavior. Seven-month-old male mice from four experimental groups [wild type (wt), $n=8$; 3xTg, $n=8$; SPKO, $n=5 ; 3 \mathrm{xTg} / \mathrm{SPKO}, n=6$ ) were used. Spatial learning was tested using the Barnes maze (Barnes, 1979). The protocol is available on-line (http://www.nature.com/ protocolexchange/protocols/349). Briefly, mice were placed on a round platform with 19 pseudo-holes and one target hole that leads to a hidden shaded small cage. After an adaptation period, mice were allowed to search for the hole for a maximum of $3 \mathrm{~min}$ while white noise and bright light were presented. Time and the number of errors (pseudo-hole visits) were measured until they found and entered the small cage. These training trials were repeated three times each day for $4 \mathrm{~d}$. At day 5 , a probe test was performed. The escape hole was blocked, and the index for recall of its location was the time mice spent in the quarter of the maze where the escape hole was located (escape quadrant).

Immunohistochemistry. Mice were anesthetized with chloral hydrate and perfused with PBS, followed by $4 \%$ paraformaldehyde (PFA). The brains were kept in $4 \%$ PFA for $24 \mathrm{~h}$ followed by $48 \mathrm{~h}$ in $30 \%$ sucrose and $1 \%$ PFA. Sixteen-micrometer-thick coronal sections were then cut with a cryostat and collected. Sections were blocked with $20 \%$ normal horse serum in $0.2 \%$ Triton X-100 containing PBS for $1 \mathrm{~h}$. Sections were incubated overnight at $4^{\circ} \mathrm{C}$ with the primary antibodies in $2 \%$ normal horse serum and $0.2 \%$ Triton X-100 in PBS [antibodies used were as follows: SP (SE-19): 1:500; Sigma-Aldrich; RyR: 1:100; catalog \#ab2868, Abcam; $\beta$-amyloid: 1:100; catalog \#6E10 BLG-803001, BioLegend; Iba-1: 1:200; catalog \#CN-019-19741, Wako; phospho-tau (p-tau; Ser202, Thr205): 1:100; catalog \#AT-8 CN-90206, Innogene Kalbiotech]. Sections were then rinsed in PBS and incubated with the biotinylated antibody in $2 \%$ normal horse serum in PBS (1:100; Jackson ImmunoResearch) for $2 \mathrm{~h}$ at room temperature followed by incubation with streptavidin (1:200; Jackson ImmunoResearch) in PBS for $1.5 \mathrm{~h}$. Confocal image stacks were taken using a Zeiss LSM 880 laser-scanning microscope equipped with an EC Plan-Neofluar $5 \times / 0.16 \mathrm{M} 27$, plan-apochromat $20 \times / 0.8$, and planapochromat $63 \times / 1.40$ oil differential interference contrast objectives. Detector and amplifier gains were initially set to obtain pixel densities within a linear range. Up to 15 images were recorded per stack. Cells, plaque counts, and fluorescent levels were measured using ImageJ software. Nine-month-old female mice $(n=18$ sections taken from three mice per group) were used in all staining except for staining for SP, where 2 -month-old male mice $(n=12$ sections taken from three animals per group) were used.

Electrophysiology. Mice were rapidly decapitated with a guillotine, their brains were removed, and the hippocampi were sliced into transverse 400 $\mu \mathrm{m}$ slices on a McIllwain tissue chopper. Slices were incubated at room temperature for $1.5 \mathrm{~h}$ in carbogenated $\left(5 \% \mathrm{CO}_{2} / 95 \% \mathrm{O}_{2}\right)$ ACSF $(124 \mathrm{~mm}$ $\mathrm{NaCl}, 4.2 \mathrm{~mm} \mathrm{KCl}, 26 \mathrm{~mm} \mathrm{NaHCO}_{3}, 1.24 \mathrm{~mm} \mathrm{KH}_{2} \mathrm{PO}_{4}, 2.5 \mathrm{~mm} \mathrm{CaCl}_{2}, 2$ $\mathrm{mM} \mathrm{MgSO}_{4}$, and $10 \mathrm{~mm}$ glucose, at pH 7.4). Recordings were made from slices in a standard interface chamber at $33.8-34.0^{\circ} \mathrm{C}$. Field EPSPs were recorded through a glass pipette containing $0.75 \mathrm{M} \mathrm{NaCl}(4 \mathrm{M} \Omega)$ in stratum radiatum of CAl region. Synaptic responses were evoked by stimulation of the Schaffer collaterals through a bipolar handmade nickel chromium electrode. In most experiments, two stimulating electrodes were placed on both sides of the recording electrode in stratum radiatum, producing similar population EPSPs and LTP (see Fig. 2). This allows testing the effect of substrates on stimulation protocol such as highfrequency stimulation (HFS) on the same slice. Evoked population EPSPs (50\% of maximum amplitude) were recorded for a stable baseline 
A

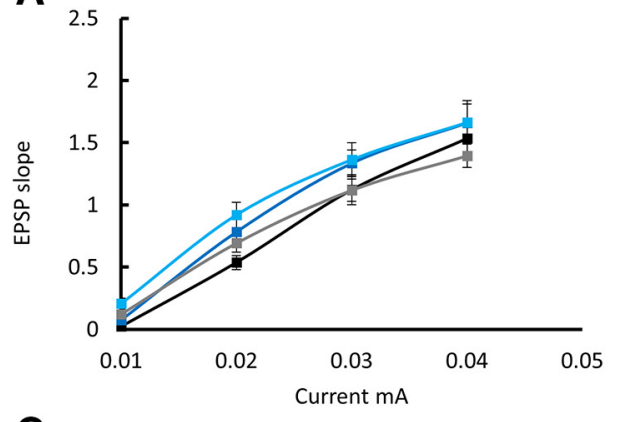

B

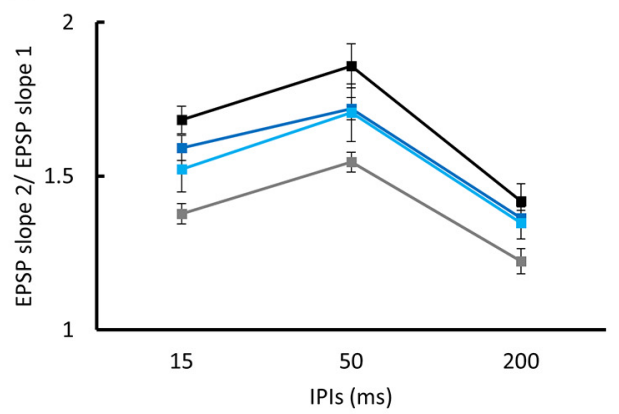

$\rightarrow-4-6-w e e k s-o l d w t$

$\rightarrow-4-6-w e e k s-o l d$ SPKO

--6 -month-old wt

C
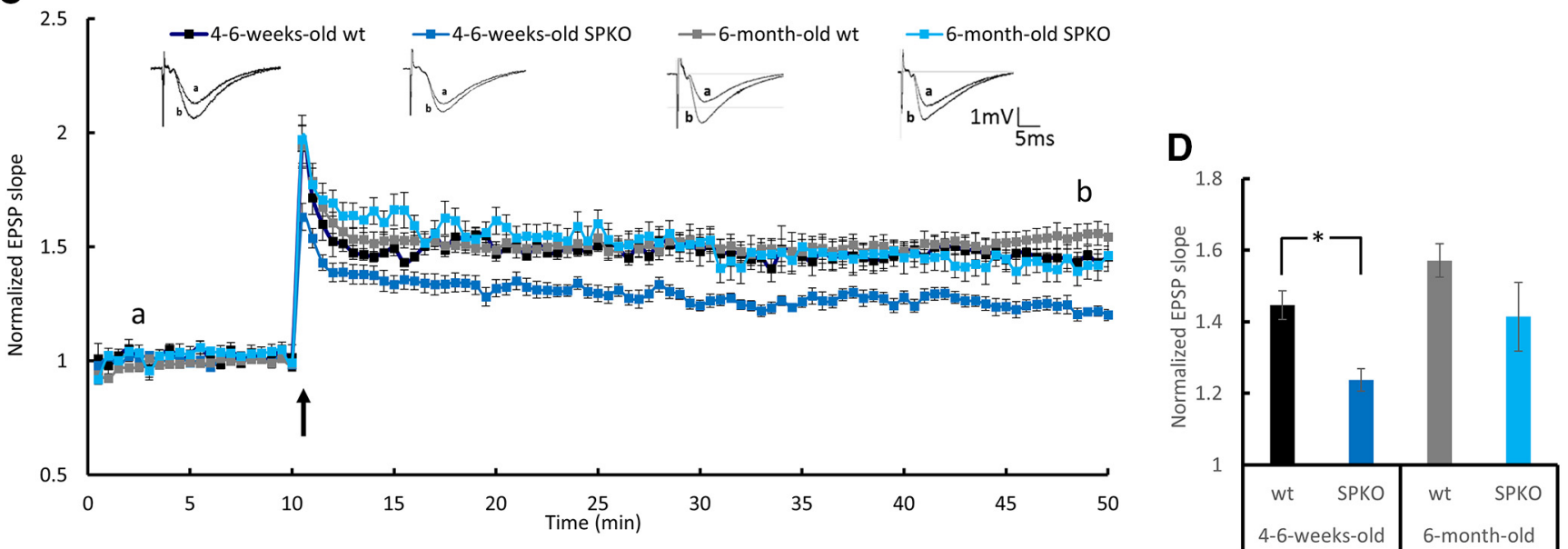

Figure 4. Young but not adult SPKO mice show LTP deficiency: extracellular field potential recordings of EPSP in CA1 stratum radiatum of the mouse hippocampus. A, Input- output curves showing EPSP slopes recorded at different stimulation intensities. $\boldsymbol{B}$, Paired-pulse ratio at three different interpulse intervals (IPIs). $\boldsymbol{C}$, Normalized EPSP slopes recorded in response to tetanic stimulation. HFS was delivered to S1, marked by a black arrow. Sample EPSPs recorded before and after HFS at the time indicated in the record are presented above. $D$, Bar graph summarizes LTP results at time point "b" showing a significant reduction in LTP in the young SPKO group compared with the wt group (wt: $n=7$ slices, $1.45 \pm 0.04 ;$ SPK0: $n=7$ slices, 1.24 $\pm 0.0 ; p<0.003$, two-sample $t$ test) that was restored in the adult SPKO group. One-month-old male mice ( $n=6$ slices taken from 3 mice per group) and 6 -month-old male mice $(n=9-15$ slices taken from $3-4$ mice/group). The 6-month-old group is the same cohort of results as presented in Figure $8 .{ }^{*} p<0.05$.

\section{A KO KO wt Heterozygote}
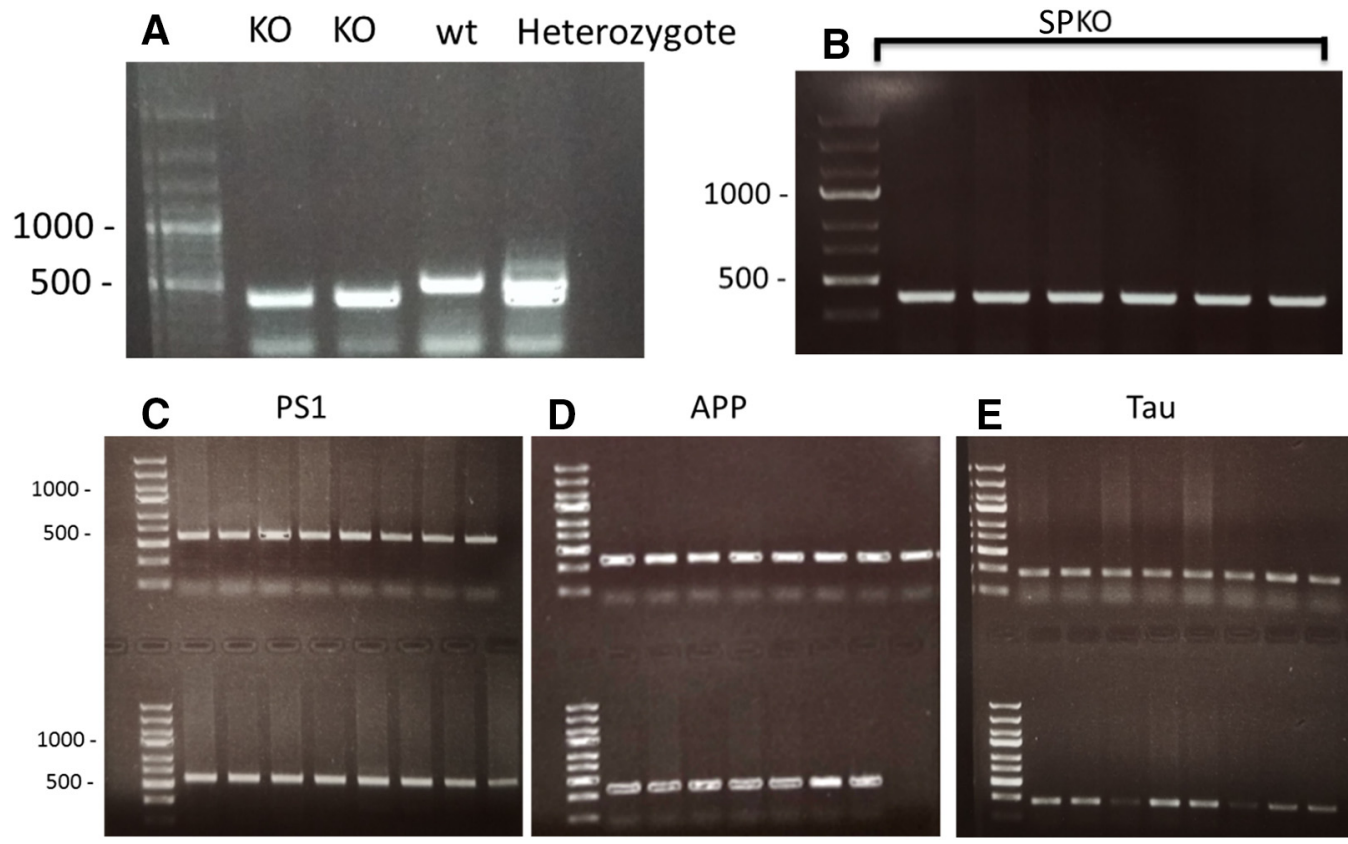

Figure 5. Genotyping of $3 x T g / S P K 0$ mouse line: representative gels of PCR results from DNA of the $3 \times T g / S P K 0$ mouse line. $A$, Example of SP gene enhanced by $P C R$ in four mice. $B-E$, $P C R$ results from mice obtained through several generations of intercrossing, showing a whole litter of mice possessing all four mutations. (SPK0, 398 bp; SP wt, 492 bp; PS1 M146V, 608 bp; APP Swed, 377 bp; Tau p301L, 254 bp). 

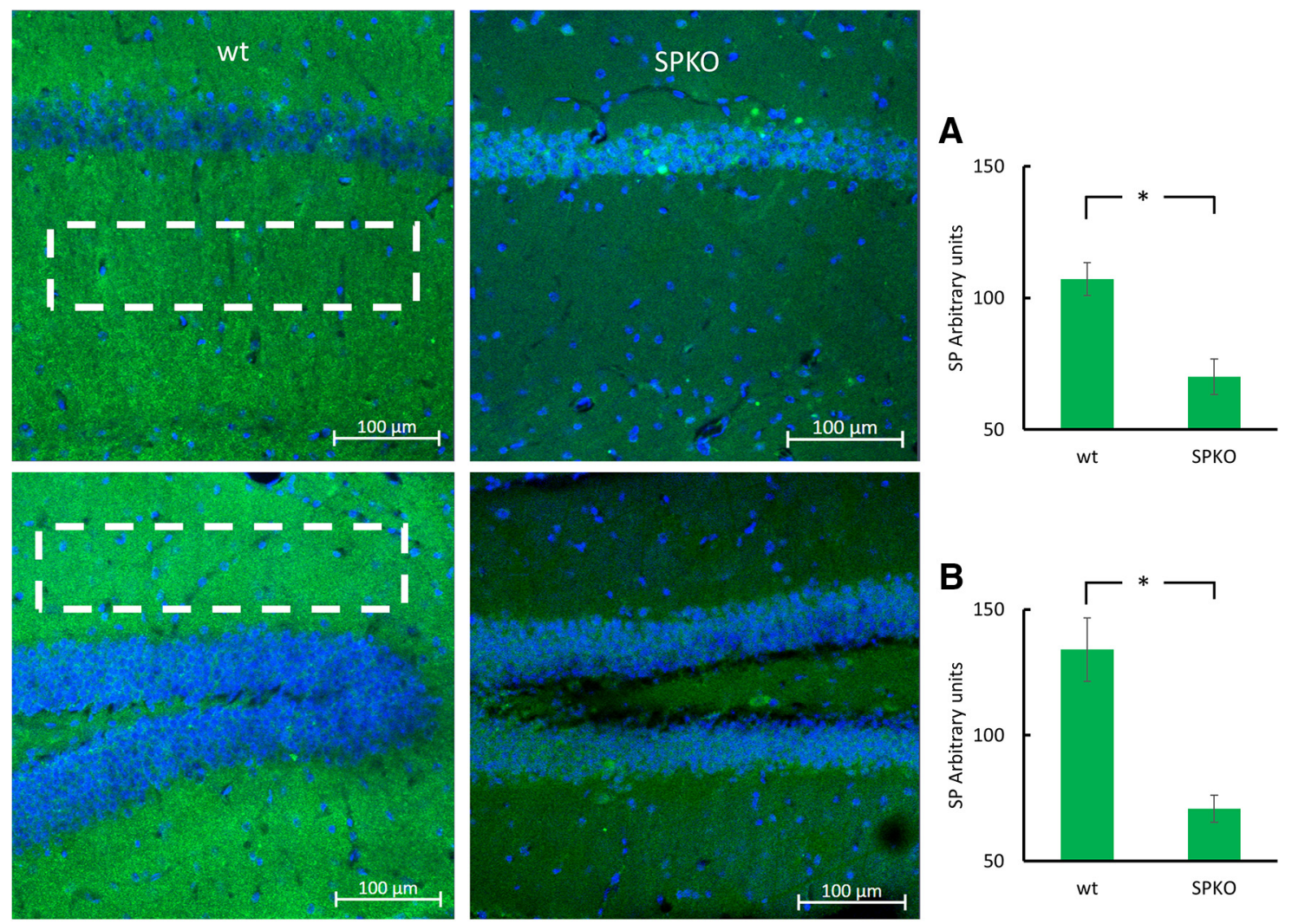

Figure 6. SPKO mice do not express SP: representative immunostaining of CA1 area (top) and DG (bottom) of brain sections immunolabeled for SP (green) and DAPI (blue). $\boldsymbol{A}$, Bar graph taken from stratum radiatum. $\boldsymbol{B}$, Bar graph taken from molecular layer of the DG (as can be seen by the white rectangles) showing significantly lower SP expression in the SPKO group ( $p<0.001$ for both areas; two-tailed $t$ test. Two-month-old male mice. $n=12$ sections taken from 3 animals/group. ${ }^{*} p<0.05$.

A

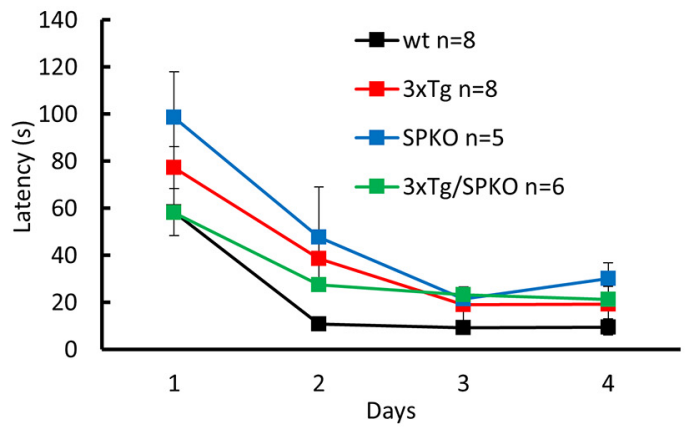

B
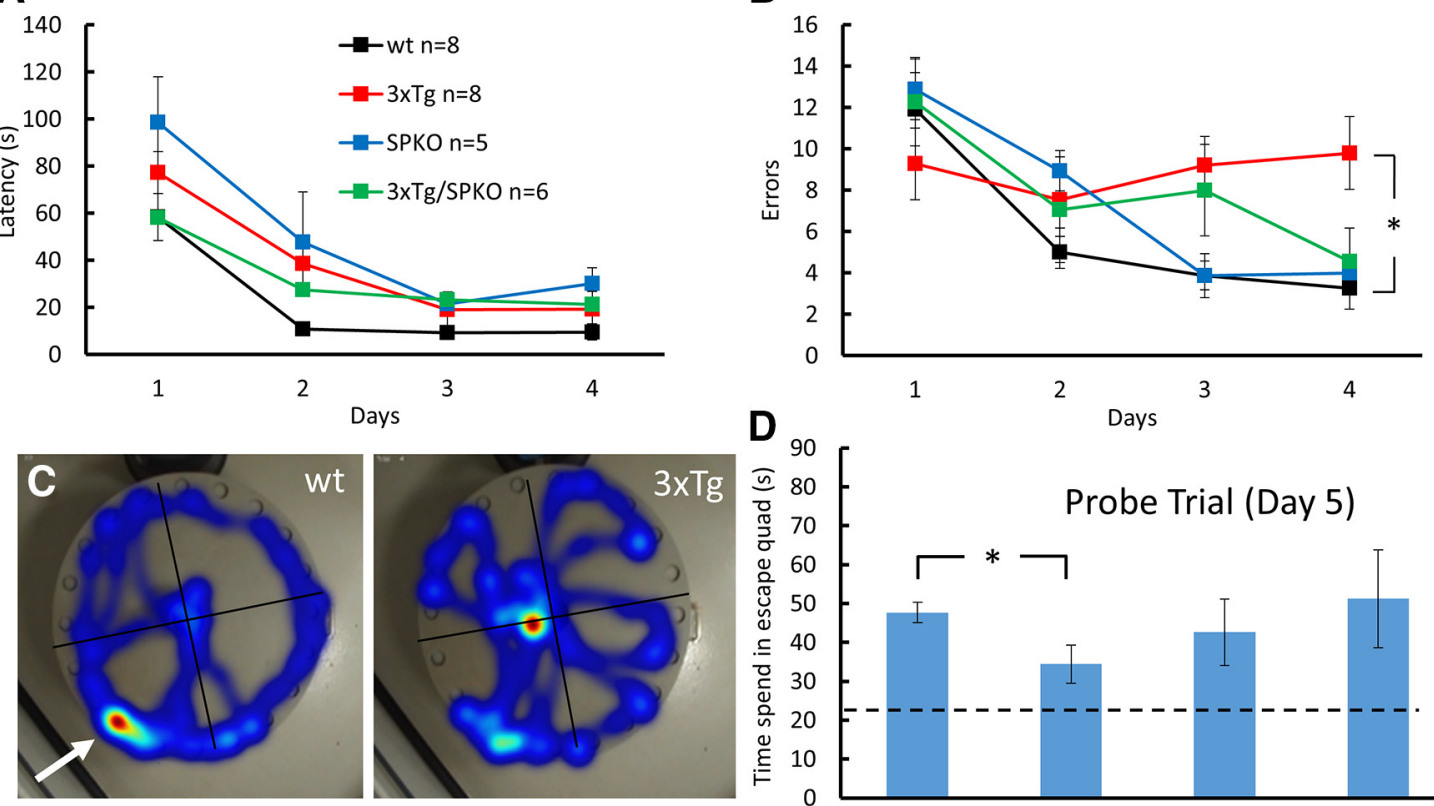

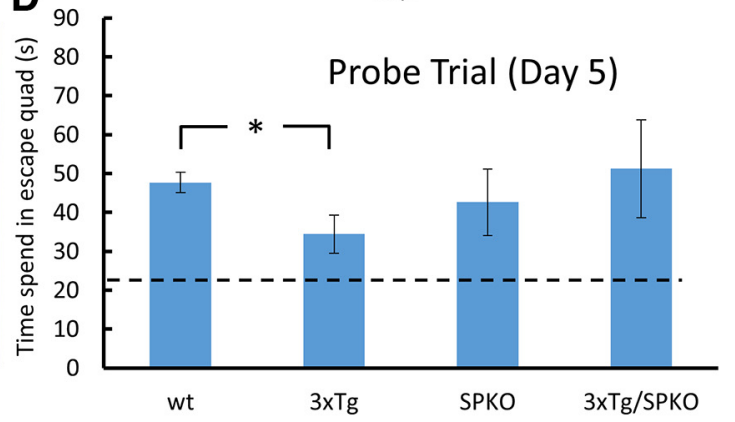

Figure 7. SP deficiency restores spatial navigation in the 3xTg mice: 7-month-old male mice were trained in the Barnes circular maze for $4 \mathrm{~d}$. A probe trial, in which the escape hole was blocked ( $\boldsymbol{C}$, white arrow), was conducted $24 \mathrm{~h}$ after the last training session. $\boldsymbol{A}, \boldsymbol{B}$, During acquisition phase, latency $(\boldsymbol{A})$ and errors $(\boldsymbol{B})$ were recorded. During the probe trial, time in the escape quadrant was recorded. All groups learned this task. $C$, However, two-way repeated-measures ANOVA revealed a significant effect for groups on errors $\left(F_{(8.36,66.86)}=2.928, p=0.038\right)$, and a Tukey HSD post hoc test indicated a significant difference between $3 \times \operatorname{Tg}$ and wt groups $(p=0.023)$. $\boldsymbol{D}$, In the probe trial, all groups displayed a search bias for the target quadrant (dashed line indicates chance level); however, a one-way ANOVA followed by post hoc test indicated a significant difference between the groups (wt, $47.68 \pm 2.653 \mathrm{~s} ; 3 \times \mathrm{xTg}, 34.4 \pm 4.92 \mathrm{~s} ; F 15=4.159, p=0.032$ ). ${ }^{*} p<0.05$. 
period of at least $10 \mathrm{~min}$. For induction of LTP, HFS [two trains, 100 pulses in $1 \mathrm{~s}(100 \mathrm{~Hz})$, at $30 \mathrm{~s}$ intervals] was delivered. For the pairedpulse stimulation protocol, two consecutive stimuli of equal intensity were delivered at varying interpulse intervals (range, 15-200 ms) to stratum radiatum. Drugs were prepared from stocks and diluted in recording medium immediately before use then applied by perfusion on the slice. Data acquisition and off-line analysis were performed using pCLAMP 9.2 (Molecular Devices) in a blind procedure, and the code was opened only after completion of individual slice data analysis. All numerical data are expressed as the mean \pm SEM, and EPSP slope changes after HFS were calculated with respect to baseline. Six-month-old male mice $(n=4-5$ slices taken from three mice per group and concentration) were used to test the effect of caffeine on synaptic property experiments in the $3 x T g$ mice. Six-month-old male mice ( $n=9-13$ slices taken from three to four mice per group) were used in experiments on the effect of caffeine on basal hippocampal synaptic transmission in the SPKO mice. Sixmonth-old male mice ( $n=9-15$ slices taken from three to four mice per group) were used to test the effects of SPKO deficiency and ryanodine on synaptic properties. Four- to sixweek-old male mice $(n=9-11$ slices taken from three mice per group) were used in the effect of SP deficiency on synaptic properties in experiments with young mice.

Experimental design and statistical analysis. Different cohorts of mice were used in each experiment. Statistical design for experiments can be found in the Results section. All statistical analyses were conducted using MATLAB software. Significant differences among groups were considered to be $<5 \%$ and were marked by the * symbol.

\section{Results}

To test whether calcium release from intracellular stores under baseline conditions and in response to tetanic stimulation is altered in the 3xTg mice, we examined the effect of caffeine (Margineanu and Klitgaard, 2004; Chakroborty et al., 2009; Wu et al., 2013). Caffeine perfusion onto hippocampal slices resulted in an increase in slope of EPSPs already at a concentration of $50 \mu \mathrm{M}$, and the effect was dose dependent (Fig. 1). Since the elevation of $\left[\mathrm{Ca}^{2+}\right] \mathrm{i}$ during HFS is essential for LTP induction, we examined whether the perfusion of the low concentration of caffeine alters EPSPs and the induction of LTP. Caffeine perfusion yielded no significant differences in the increase in EPSPs between the wt and $3 \mathrm{xTg}$ groups (Fig. 2B). Interestingly, LTP that was deficient in $3 \mathrm{xTg}$ mice compared with control wt mice was restored back to normal after the perfusion of $50 \mu \mathrm{M}$ caffeine for $20 \mathrm{~min}$ (Fig. $2 C, D)$. There was a significant reduction in paired-pulse facilitation at a $50 \mathrm{~ms}$ interval following $50 \mu \mathrm{M}$ caffeine perfusion (Fig. $2 A$ ), indicating that the changes generated by caffeine were partly presynaptic. The effect of caffeine on LTP induction indicates a higher release of calcium from RyR in the $3 x \mathrm{Tg}$ mice following a tetanic stimulation.

$\mathrm{SP}$ is associated with RyR in dendritic spines (Vlachos et al., 2009). To study the role of SP deficiency on calcium release from stores, the effect of $5 \mathrm{~mm}$ caffeine on basal hippocampal synaptic transmission was compared between the SPKO and wt mice. Cafmice/group.

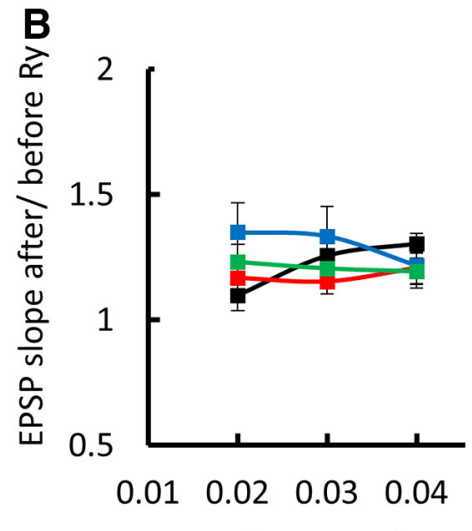

Current mA

\section{Before}
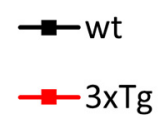

$\rightarrow$ SPKO

$-3 \times \operatorname{Tg} / \mathrm{SPKO}$
After (Ry)

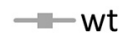

$--3 \times \operatorname{Tg}$

- SPKO $-3 \times \operatorname{Tg} / \mathrm{SPKO}$

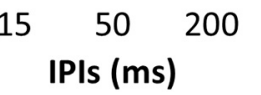
PKO

Figure 8. 3xTg/SPKO mouse line exhibits no differences in tissue viability and paired-pulse facilitation: extracellular field ifferent stimulation intensities. $\boldsymbol{B}$, EPSP slope after/before $10 \mathrm{~min}$ of $1 \mu \mathrm{m}$ Ry perfusion. $\boldsymbol{C}$, Paired-pulse ratio at three different interpulse intervals (IPIs) before and after 10 min of $1 \mu \mathrm{m}$ Ry perfusion. Six-month-old male mice; $n=9-15$ slices taken from 3-4

feine facilitation of EPSP was significantly lower in the SPKO mice (Fig. 3D). In addition, $5 \mathrm{~mm}$ caffeine reduced paired-pulse facilitation in $15 \mathrm{~ms}$ interpulse intervals in the wt group, and in 50 ms intervals in both groups (Fig. $3 A$ ), suggesting that caffeine has a presynaptic effect.

It has been reported (Deller et al., 2003) that SPKO slices express a reduced ability to generate LTP. In contrast, Zhang et al. (2013) found that this deficiency is age dependent. To clarify this discrepancy in our animals, we compared the ability to express LTP in both young (4- to 6-week old) and adult (6-month-old) SPKO and wt mice. Figure 4). While young SPKO mice expressed a significantly reduced ability to form LTP, the older cohort was not different from controls (Fig. 4). Consequently, further experiments were performed with the older cohort of mice.

To examine the role of SP in the $3 x T g$ AD syndrome, we cross-bred SPKO with 3xTg mice to obtain a mouse line combining SPKO and the three mutations of the 3xTg mice (Fig. 5). We first validated that SPKO mice do not immunostain for synaptopodin. SPKO mice show only background fluorescence that was significantly lower than that of the wt mice (Fig. 6). We then commenced a series of experiments to examine the functional relevance of the combined 3xTg/SPKO genes. This consisted of two types of experiments, the behavioral and electrophysiological studies.

In the spatial learning task, the performance of the four groups of mice in the Barnes maze was assessed. While the 3xTg could not learn the spatial task, SP deficiency restored this function back to wt levels in both of the errors made while learning (Fig. $7 B$ ) and in the time spent in the escape quadrant in the probe trail 


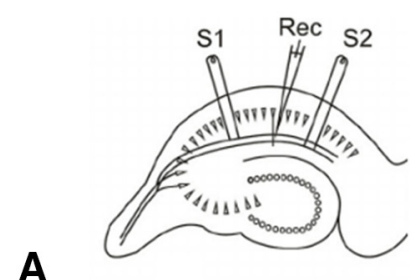

A

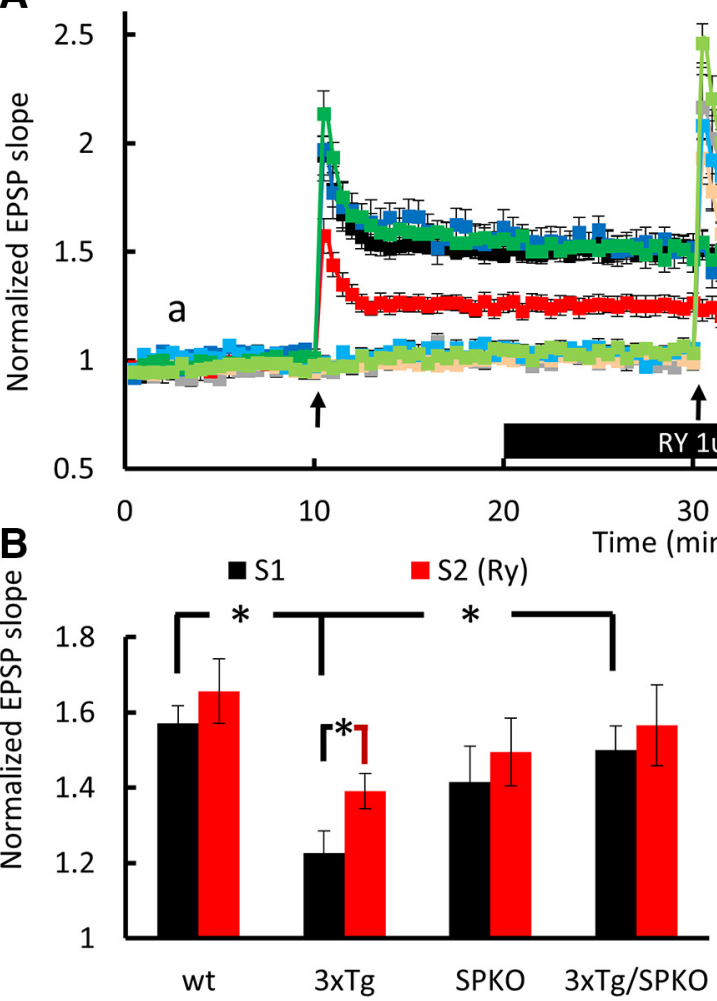

$3 \times T g$ SPKO

3xTg/SPKO

S1

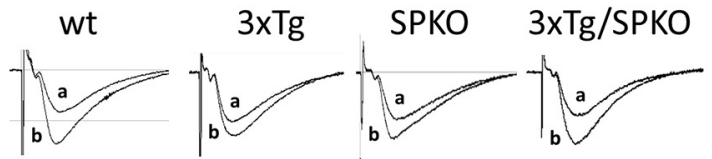

S2

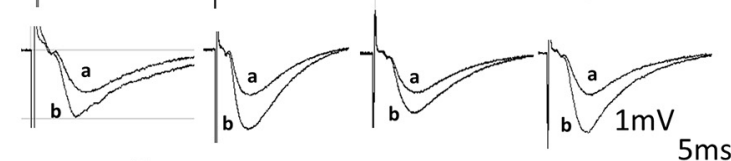

b

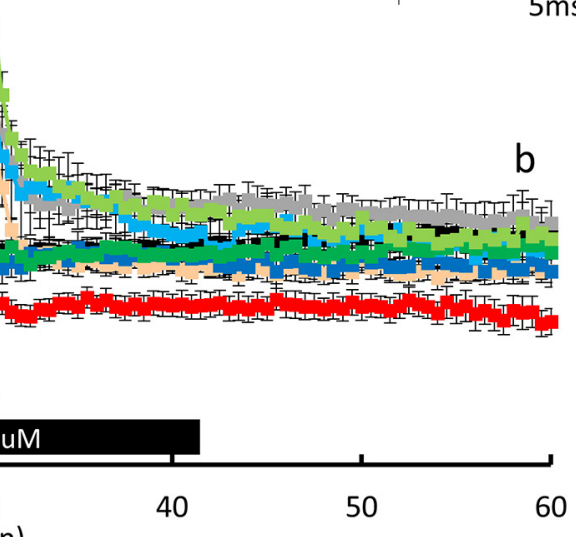

S1

S2

$\rightarrow-w t$

$-\mathrm{wt}$

$-3 \times \operatorname{Tg}$

$--3 \times \operatorname{Tg}$

$\rightarrow-S P K O$

$\rightarrow$ SPKO

$\rightarrow-3 \times T g / S P K O \quad-3 \times T g / S P K O$

Figure 9. 3xTg/SPKO mouse slices display restored LTP while Ry facilitates LTP only in 3xTg slices. $A$, Extracellular EPSPs recorded in stratum radiatum of the hippocampus. Normalized EPSP slopes recorded in response to stimulation of two pathways as presented in the diagram at top left. First, HFS was delivered to the S1 pathway, and the second HFS was delivered to the S2 pathway, both of which are marked by black arrows. Slices were perfused with $1 \mu \mathrm{m}$ Ry during the bar shown below the record. Sample EPSPs recorded before and after HFS at the time indicated in the record are presented above. $\boldsymbol{B}$, Bar graph summarizes LTP results at time point b showing significant reduction in LTP in the 3xTg group compared with the wt group (wt, 1.5709 $\pm 0.046 ; 3 \times T g, 1.2266 \pm$ $0.0589 ; p<0.001$, two-sample $t$ test) that was restored in the 3xTg/SPK0 group back to normal ( $p<0.005$, two-sample $t$ test), and significant elevation in LTP with Ry in the $3 \times T$ Trg group (before, $1.2266 \pm 0.0589 ;$ after, $1.3907 \pm 0.0047 ; p<0.042$, two-sample $t$ test). Six-month-old male mice; $n=9-15$ slices taken from 3- 4 mice/group. ${ }^{*} p<0.05$.
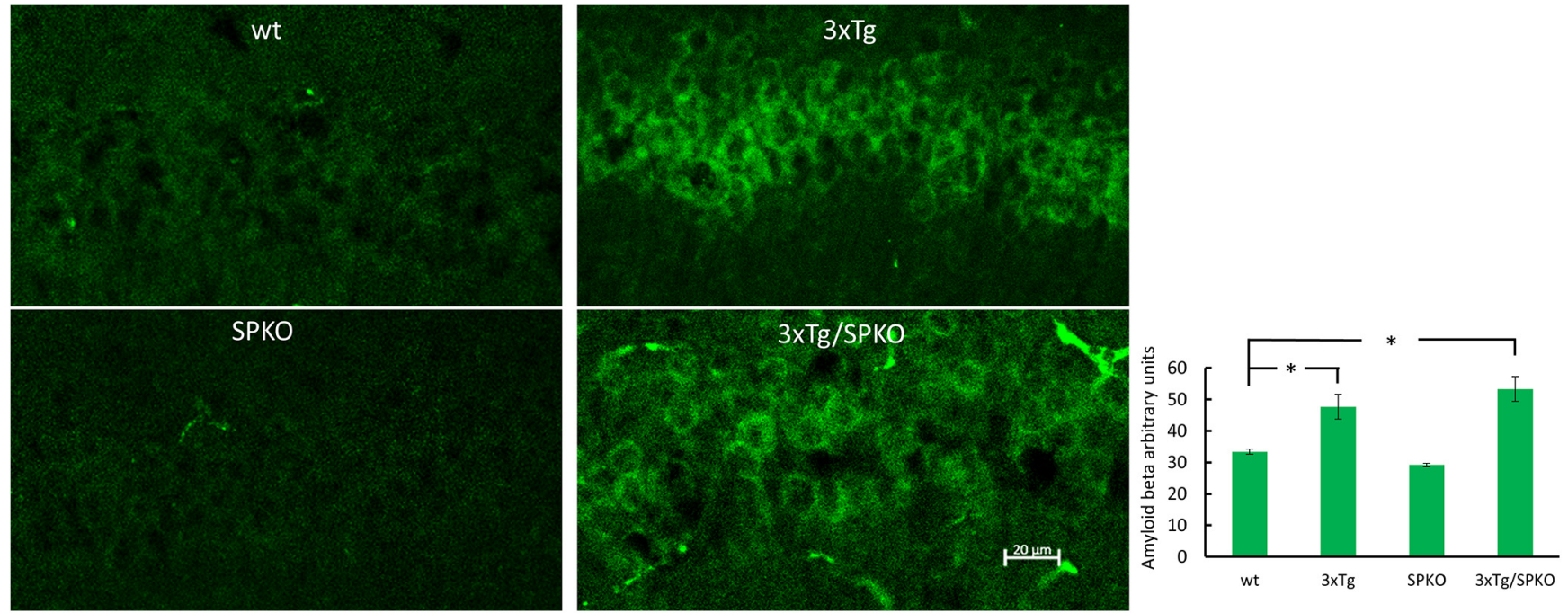

Figure 10. 3xTg and 3xTg/SPKO express more intracellular $\beta$-amyloid: representative immunostaining of CA1 area of hippocampal sections immunolabeled for $\beta$-amyloid (green). Bar graph showing significant differences between the control and 3xTg groups and between the wt and 3xTg/SPKO groups found using one-way ANOVA with Tukey HSD post hoc test (wt, 33.39 $\pm 0.81 ; 3 \times T g, 47.68 \pm 3.9$; 3xTg/SPK0, $53.3 \pm 3.95 ; \mathrm{F} 3=8.551 ; p<0.001 ;$ post hoc test: wtvs $3 \times \mathrm{Tg}, p=0.0147 ;$ wtvs $3 \times \mathrm{Tg} / \mathrm{SPKO}, p=0.0016)$. Nine-month-old female mice; $n=18$ sections taken from 3 animals $/$ group. ${ }^{*} p<0.05$. 

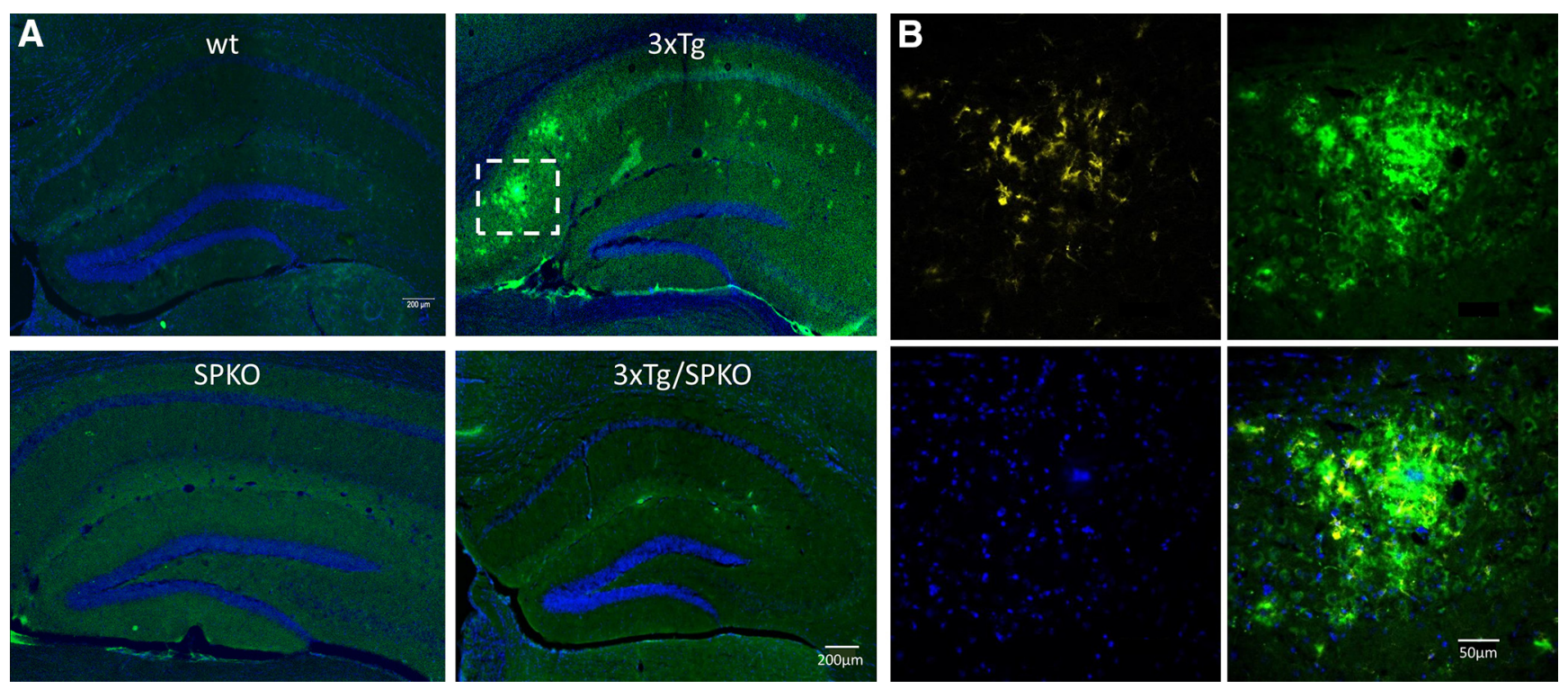

Figure 11. $\quad \beta$-Amyloid plaques detected in the 3xTg: Representative immunostaining of hippocampal sections. A, Immunolabeled for $\beta$-amyloid (green) and DAPI (blue). $\boldsymbol{B}$, Enlargement of representative $\beta$-amyloid plaque colocalized with activated microglia (yellow). Nine-month-old female mice; $n=18$ sections taken from 3 animals/group.

(Fig. 7D). No differences were found in latency to find the escape hole (Fig. 7A), suggesting that differences in motility or emotionality do not underlie the cognitive deficit.

To test the effect of SP deficiency on the reduction in synaptic plasticity seen in the $3 \times \mathrm{Tg}$ mice, field potentials were compared in CA1 region of hippocampal slices of the four groups of mice. In these experiments, we used ryanodine (Ry; $1 \mu \mathrm{M})$ instead of caffeine, to eliminate the possible presynaptic side effects of caffeine. Although the pharmacological mechanism differs between the two substrate, both can be used to test the effects of increased release of calcium from the RyR (Meissner, 1986; Chakroborty et al., 2009; Grigoryan et al., 2012). First, input-output relations were measured before and after exposure of the slices to $1 \mu \mathrm{M}$ Ry, a RyR agonist (Mellentin et al., 2007; Grigoryan et al., 2012). No differences were found among the groups (Fig. $8 A$ ), and there was not an effect of Ry on these measurements (Fig. $8 B$ ). Thereafter, a paired-pulse protocol was used to tentatively localize the site of action of ryanodine. There were no significant paired-pulse differences among the groups (Fig. $8 C$ ), indicating that Ry at this concentration was not effective on baseline synaptic responses. For testing synaptic plasticity, we applied tetanic stimulation to two pathways, before and during the perfusion of Ry at $1 \mu \mathrm{M}$. While LTP was deficient in the $3 \times \mathrm{xTg}$ mice, it was restored back to the level of wt LTP in the $3 \times \mathrm{Tg} / \mathrm{SPKO}$ group (Fig. 9). Furthermore, the facilitating effect of Ry on LTP was found only in the 3xTg group, but not in the wt or the SPKO slices, suggesting that calcium release from stores is more effective in this group following tetanic stimulation. Overall, these results indicate that lack of SP ameliorates the LTP deficiency found in $3 \times \mathrm{Tg}$ mice and provides evidence for the relevance of the RyR in the restoration of the LTP mechanism.
To test whether SP deficiency affects the morphological AD markers found in the 3xTg mice, we analyzed brain sections for immunohistochemistry in 9-month-old female mice, which are known to be more sensitive to the $3 \mathrm{xTg}$ transgenes (Yang et al., 2018). Brain sections from the four groups of mice were stained with specific antibodies for $\beta$-amyloid and microglia. Both 3xTg and $3 \mathrm{xTg} / \mathrm{SPKO}$ mouse groups expressed more intracellular $\beta$-amyloid (Fig. 10). However, there were no extracellular $\beta$-amyloid plaques in the $3 \times \mathrm{TT} / \mathrm{SPKO}$ mice, which were clearly detected in the $3 \times \mathrm{xTg}$ group and colocalized with activated microglia (Fig. 11). Moreover, immunostaining for p-tau (a marker of $\mathrm{AD}$; Oddo et al., 2003) revealed no significant expression of p-tau in the $3 \mathrm{xTg} / \mathrm{SPKO}$ mice, which had been conspicuous in the $3 \times \mathrm{Tg}$ mice (Fig. 12). To test for the differential expression of RyR in the different groups, brain sections from 9-month-old mice were immunostained using fluorescently labeled antibodies for RyR. As expected, the 3xTg mice expressed higher levels of RyR than wt mice (Fig. 13). Interestingly, RyR expression was significantly lower in the $3 \mathrm{xTg} / \mathrm{SPKO}$ mice compared with the $3 \mathrm{xTg}$ mice (Fig. 13). 

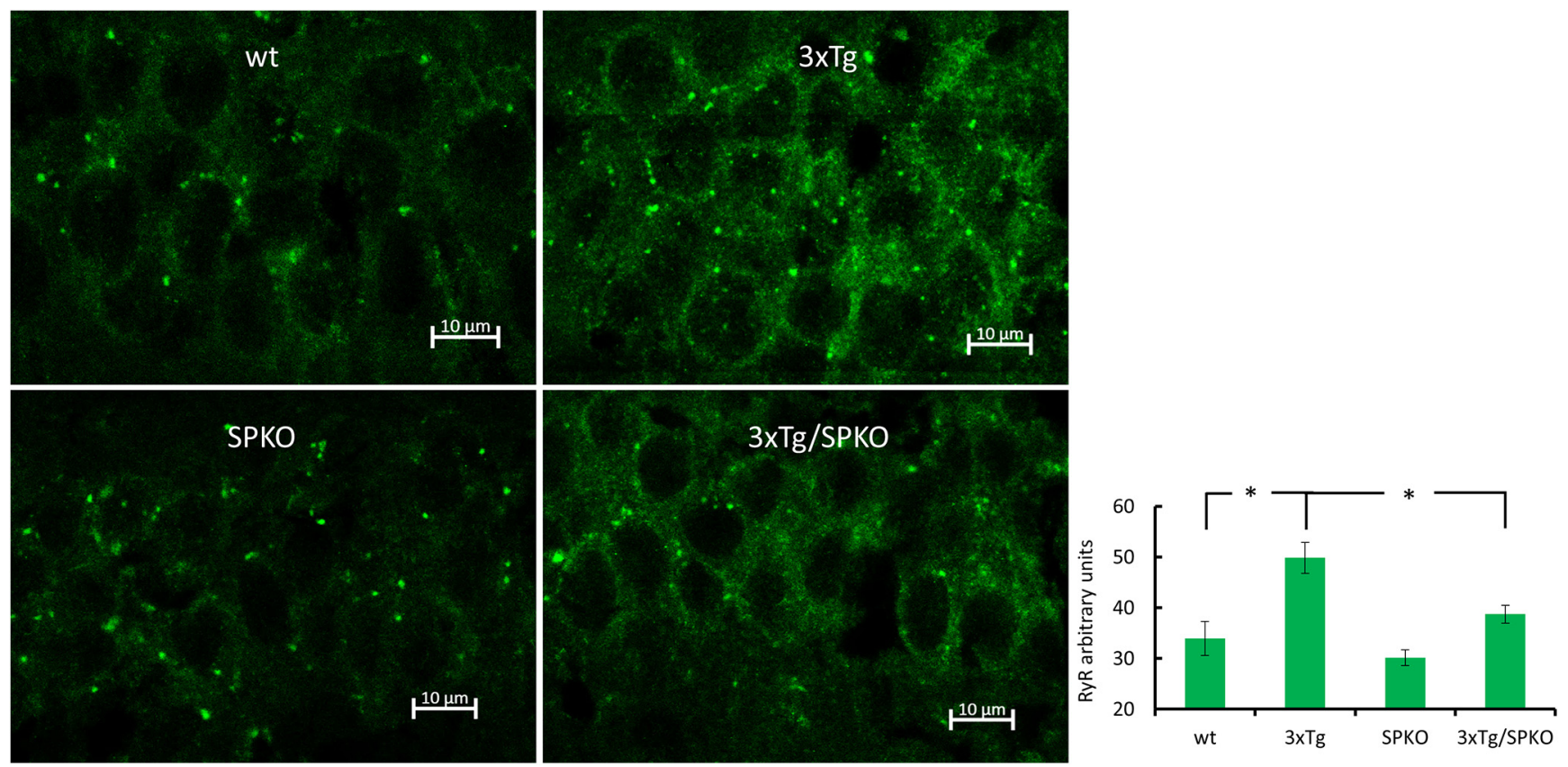

Figure 13. 3xTg mice express elevated levels of RyR: representative immunostaining of stratum pyramidale of (A1 area of brain sections immunolabeled for RyR (green). Bar graph showing significant differences between control and 3xTg groups and between 3xTg and 3xTg/SPKO groups found using one-way ANOVA with Tukey HSD post hoc test (wt, 33.944 $\pm 3.346 ; 3 \times T g, 49.846 \pm$ $3.062 ; 3 \times T g / S P K 0,38.732 \pm 1.758 ; \mathrm{F} 3=25.904 ; p<0.001 ;$ post hoc test: wt vs $3 \times \operatorname{Tg}, p=0.0013 ; 3 \times \operatorname{Tg}$ vs $3 \times \mathrm{Tg} / \mathrm{SPKO}, p=0.0034)$. Nine-month-old female mice; $n=18$ sections taken from 3 animals/group. ${ }^{*} p<0.05$.

\section{Discussion}

The present study was designed to promote better understanding of the abnormalities of calcium homeostasis in a mouse model of AD. We combined a well characterized AD model (3xTg), which has a high density of RyR with the SPKO mouse, which is reported to express reduced efficacy of RyR, and examined the effect of SP deficiency on symptoms of AD. We did not find an effect of SPKO by itself on RyR expression levels (Fig. 13); however, we cannot exclude alterations in RyR localization and proximity to spines, as suggested previously (Vlachos et al., 2009). In addition, we did not find the reduction in hippocampusdependent properties such as LTP (Fig. 4) and spatial learning (Fig. 7) in 6-month-old SPKO mice, as reported previously (Deller et al., 2003). The discordance between our data and earlier reports (Deller et al., 2003; Grigoryan and Segal, 2016) regarding LTP and spatial learning in SPKO can be explained by age differences. While we found LTP deficiency in 4- to 6-week-old mice, Deller et al. (2003) used adult mice without specifying their age, and Grigoryan and Segal (2016) used 2- to 3-month-old mice; in the present study, we did not find a reduction in LTP in 6-month-old SPKO mice. Moreover, a reduction of LTP was reported to be age dependent and was not present in 6-month-old SPKO mice (Zhang et al., 2013). The facilitating effect of caffeine and Ry on LTP that we found together with the high expression of RyR in the 3xTg mice imply that calcium release from stores is enhanced in the AD model, which has been suggested previously (Popugaeva and Bezprozvanny, 2013; Chakroborty and Stutzmann, 2014; Briggs et al., 2017). As part of the effort to restore calcium homeostasis in a PS1 FAD (familial AD) mutation, it was shown that altering the expression or function of RyR has protective effects in some cases in AD mouse models (Liu et al., 2014; Shi et al., 2018). In addition, long-term treatment with the RyR blocker dantrolene reduces cognitive decline and amyloid $\beta$ plaques in the 3xTg mice (Peng et al., 2012; Wu et al., 2015). Our findings also support earlier work performed in young (6- to 8 -week-old) 3xTg mice showing a larger increase than wt mice in RyR-evoked calcium release in response to synaptic stimulation (Chakroborty et al., 2009). In addition, a study in another AD model (APP/PS1) demonstrated that RyR priming reestablishes plasticity (Li et al., 2017). AD mouse models that harbor PS1 mutation release more calcium ions from intracellular stores in response to synaptic stimulation (Cheung et al., 2008; Chakroborty et al., 2009; Chakroborty and Stutzmann, 2014). However, despite the positive correlation between elevated $\left[\mathrm{Ca}^{2+}\right] \mathrm{i}$ and LTP, these mice exhibit a reduction in LTP. This implies that other mechanisms are involved in this deficit. In the AD cascade, it is unclear whether an elevation in RyR expression is part of a mechanism that compensates for the lack of synaptic plasticity or that other mechanisms are activated to reduce the response to the elevation in $\left[\mathrm{Ca}^{2+}\right]$ i that occurs due to higher RyR expression. At any rate, the changes in calcium regulation and LTP occur before other $\mathrm{AD}$ symptoms such as $\beta$-amyloid aggregations seen at 9 months of age. Therefore, calcium regulation mechanisms have been suggested to be a suitable target for the development of therapeutic approaches (Chakroborty and Stutzmann, 2014; Briggs et al., 2017). We found that the combined mouse line of $3 \times$ Tg and SPKO ameliorates AD symptoms such as LTP deficiency (Fig. 9), impaired spatial navigation (Fig. 7), $\beta$-amyloid plaques, activated microglia (Fig. 11), and p-tau overexpression (Fig. 12). In addition, the 3xTg/SPKO mice exhibit restored levels of RyR back to normal range (Fig. 13). The finding of a clear increase in intracellular $\beta$-amyloid both in $3 x \mathrm{Tg}$ and in $3 \mathrm{xTg} /$ SPKO groups (Fig. 10) is expected probably because both lines contain the APPSwe mutation. Interestingly, plaques were detected only in the $3 x T$ g group. This requires further investigation to specify the different forms of $\beta$-amyloid found in both lines. It is important to note that this study shows amelioration of $\mathrm{AD}$ symptoms only in the $3 \times \mathrm{Tg}$ mouse model, and it would be of 
interest to generalize the effect of SP deficiency in other AD mouse models.

Together, our data support the involvement of ryanodine and calcium stores in the early stage of development of $\mathrm{AD}$, and promotes the "calcium hypothesis" as a leading cause of AD to be considered as a potential therapeutic avenue of the disease.

\section{References}

Barnes CA (1979) Memory deficits associated with senescence: a neurophysiological and behavioral study in the rat. J Comp Physiol Psychol 93:74-104.

Briggs CA, Chakroborty S, Stutzmann GE (2017) Emerging pathways driving early synaptic pathology in Alzheimer's disease. Biochem Biophys Res Commun 483:988-997.

Bruno AM, Huang JY, Bennett DA, Marr RA, Hastings ML, Stutzmann GE (2012) Altered ryanodine receptor expression in mild cognitive impairment and Alzheimer's disease. Neurobiol Aging 33:1001.e1-6.

Chakroborty S, Stutzmann GE (2014) Calcium channelopathies and Alzheimer's disease: insight into therapeutic success and failures. Eur J Pharmacol 739:83-95.

Chakroborty S, Goussakov I, Miller MB, Stutzmann GE (2009) Deviant ryanodine receptor-mediated calcium release resets synaptic homeostasis in presymptomatic 3xTg-AD mice. J Neurosci 29:9458-9470.

Cheung KH, Shineman D, Müller M, Cárdenas C, Mei L, Yang J, Tomita T, Iwatsubo T, Lee VM, Foskett JK (2008) Mechanism of Ca2 + disruption in Alzheimer's disease by presenilin regulation of InsP3 receptor channel gating. Neuron 58:871-883.

Clark JK, Furgerson M, Crystal JD, Fechheimer M, Furukawa R, Wagner JJ (2015) Alterations in synaptic plasticity coincide with deficits in spatial working memory in presymptomatic $3 \mathrm{xTg}-\mathrm{AD}$ mice. Neurobiol Learn Mem 125:152-162.

Counts SE, Alldred MJ, Che S, Ginsberg SD, Mufson EJ (2014) Synaptic gene dysregulation within hippocampal CA1 pyramidal neurons in mild cognitive impairment. Neuropharmacology 79:172-179.

Datta A, Chai YL, Tan JM, Lee JH, Francis PT, Chen CP, Sze SK, Lai MKP (2017) An iTRAQ-based proteomic analysis reveals dysregulation of neocortical synaptopodin in Lewy body dementias. Mol Brain 10:36.

Del Prete D, Checler F, Chami M (2014) Ryanodine receptors: physiological function and deregulation in Alzheimer disease. Mol Neurodegener 9:21.

Deller T, Korte M, Chabanis S, Drakew A, Schwegler H, Stefani GG, Zuniga A, Schwarz K, Bonhoeffer T, Zeller R, Frotscher M, Mundel P (2003) Synaptopodin-deficient mice lack a spine apparatus and show deficits in synaptic plasticity. Proc Natl Acad Sci U S A 100:10494-10499.

Deller T, Bas Orth C, Del Turco D, Vlachos A, Burbach GJ, Drakew A, Chabanis S, Korte M, Schwegler H, Haas CA, Frotscher M (2007) A role for synaptopodin and the spine apparatus in hippocampal synaptic plasticity. Ann Anat 189:5-16.

Grigoryan G, Segal M (2016) Ryanodine-mediated conversion of STP to LTP is lacking in synaptopodin-deficient mice. Brain Struct Funct 221:2393-2397.

Grigoryan G, Korkotian E, Segal M (2012) Selective facilitation of LTP in the ventral hippocampus by calcium stores. Hippocampus 22:1635-1644.

Grigoryan G, Biella G, Albani D, Forloni G, Segal M (2014) Stress impairs synaptic plasticity in triple-transgenic Alzheimer's disease mice: rescue by ryanodine. Neurodegener Dis 13:135-138.

Jedlicka P, Deller T (2017) Understanding the role of synaptopodin and the spine apparatus in Hebbian synaptic plasticity-new perspectives and the need for computational modeling. Neurobiol Learn Mem 138:21-30.

Kelliher M, Fastbom J, Cowburn RF, Bonkale W, Ohm TG, Ravid R, Sorrentino V, O'Neill C (1999) Alterations in the ryanodine receptor calcium release channel correlate with Alzheimer's disease neurofibrillary and beta-amyloid pathologies. Neuroscience 92:499-513.

Khachaturian ZS (1989) Calcium, membranes, aging, and Alzheimer's disease. introduction and overview. Ann N Y Acad Sci 568:1-4.

Korkotian E, Segal M (2011) Synaptopodin regulates release of calcium from stores in dendritic spines of cultured hippocampal neurons. J Physiol 589:5987-5995.

Li Q, Navakkode S, Rothkegel M, Soong TW, Sajikumar S, Korte M (2017) Metaplasticity mechanisms restore plasticity and associativity in an animal model of Alzheimer's disease. Proc Natl Acad Sci U S A 114: $5527-5532$.

Liu J, Supnet C, Sun S, Zhang H, Good L, Popugaeva E, Bezprozvanny I (2014) The role of ryanodine receptor type 3 in a mouse model of Alzheimer disease. Channels (Austin) 8:230-242.

Margineanu DG, Klitgaard H (2004) Caffeine-induced epileptiform field potentials in rat hippocampal slices: a pharmacological characterization. Neuropharmacology 47:926-934.

Mattson MP (2010) ER calcium and Alzheimer's disease: in a state of flux. Sci Signal 3:pe10.

Meissner G (1986) Ryanodine activation and inhibition of the Ca2+ release channel of sarcoplasmic reticulum. J Biol Chem 261:6300-6306.

Mellentin C, Jahnsen H, Abraham WC (2007) Priming of long-term potentiation mediated by ryanodine receptor activation in rat hippocampal slices. Neuropharmacology 52:118-125.

Oddo S, Caccamo A, Shepherd JD, Murphy MP, Golde TE, Kayed R, Metherate R, Mattson MP, Akbari Y, LaFerla FM (2003) Triple-transgenic model of Alzheimer's disease with plaques and tangles: intracellular abeta and synaptic dysfunction. Neuron 39:409-421.

Peng J, Liang G, Inan S, Wu Z, Joseph DJ, Meng Q, Peng Y, Eckenhoff MF, Wei H (2012) Dantrolene ameliorates cognitive decline and neuropathology in Alzheimer triple transgenic mice. Neurosci Lett 516:274-279.

Popugaeva E, Bezprozvanny I (2013) Role of endoplasmic reticulum Ca2+ signaling in the pathogenesis of Alzheimer disease. Front Mol Neurosci 6:29.

Reddy PH, Mani G, Park BS, Jacques J, Murdoch G, Whetsell W Jr, Kaye J, Manczak M (2005) Differential loss of synaptic proteins in Alzheimer's disease: implications for synaptic dysfunction. J Alzheimers Dis 7:103117.

Shi Y, Wang Y, Wei H (2018) Dantrolene: from malignant hyperthermia to Alzheimer's disease. CNS Neurol Disord Drug Targets. Advance online publication. Retrieved March 13, 2019. doi:10.2174/ 1871527317666180619162649.

Smith IF, Hitt B, Green KN, Oddo S, LaFerla FM (2005) Enhanced caffeineinduced $\mathrm{Ca} 2+$ release in the $3 \mathrm{xTg}-\mathrm{AD}$ mouse model of Alzheimer's disease. J Neurochem 94:1711-1718.

Stutzmann GE, Mattson MP (2011) Endoplasmic reticulum $\mathrm{Ca}(2+)$ handling in excitable cells in health and disease. Pharmacol Rev 63:700-727.

Stutzmann GE, Smith I, Caccamo A, Oddo S, Laferla FM, Parker I (2006) Enhanced ryanodine receptor recruitment contributes to $\mathrm{Ca}^{2+}$ disruptions in young, adult, and aged Alzheimer's disease mice. J Neurosci 26:5180-5189.

Vlachos A, Korkotian E, Schonfeld E, Copanaki E, Deller T, Segal M (2009) Synaptopodin regulates plasticity of dendritic spines in hippocampal neurons. J Neurosci 29:1017-1033.

Vlachos A, Ikenberg B, Lenz M, Becker D, Reifenberg K, Bas-Orth C, Deller T (2013) Synaptopodin regulates denervation-induced homeostatic synaptic plasticity. Proc Natl Acad Sci U S A 110:8242-8247.

Wu B, Yamaguchi H, Lai FA, Shen J (2013) Presenilins regulate calcium homeostasis and presynaptic function via ryanodine receptors in hippocampal neurons. Proc Natl Acad Sci U S A 110:15091-15096.

Wu Z, Yang B, Liu C, Liang G, Eckenhoff MF, Liu W, Pickup S, Meng Q, Tian Y, Li S, Wei H (2015) Long-term dantrolene treatment reduced intraneuronal amyloid in aged Alzheimer triple transgenic mice. Alzheimer Dis Assoc Disord 29:184-191.

Yang JT, Wang ZJ, Cai HY, Yuan L, Hu MM, Wu MN, Qi JS (2018) Sex differences in neuropathology and cognitive behavior in APP/PS1/tau triple-transgenic mouse model of Alzheimer's disease. Neurosci Bull 34:736-746.

Zhang XL, Pöschel B, Faul C, Upreti C, Stanton PK, Mundel P (2013) Essential role for synaptopodin in dendritic spine plasticity of the developing hippocampus. J Neurosci 33:12510-12518. 